\title{
Towards Sustainable Development: Measuring Environmental Total Factor Productivity in Egypt
}

\author{
By Iman Al-Ayouty ${ }^{1}$, Hoda Hassaballa ${ }^{2}$
}

\begin{abstract}
Egypt's heavy reliance on energy- and capital-intensive industries currently hinders its drive towards achieving sustainable development goals. This paper studies environmental total factor productivity (ETFP) for ten energy-intensive industries using the Malmquist index and data envelopment analysis (DEA) for the period 2002-2014. Through incorporating $\mathrm{CO}_{2}$ emissions by energy intensive industries, DEA helps identify both environmentally-efficient and inefficient industries. Findings indicate that: i) ETFP has remained almost unchanged for the 10 industries, with 'technical progress' improvement almost fully outweighed by an efficiency deterioration, ii) excluding the environmental component indeed yields overestimated total factor productivity (TFP). In its estimation of ETFP, the paper adds to exiting empirical literature since no similar estimation has been done for Egypt. Results may be relevant to other countries with similar industrial structures. Policy implications include the reliance on renewable sources of energy, bearing directly on the achievement of the seventh, ninth and twelfth SDG goals.
\end{abstract}

Keywords: environmental total factor productivity; energy intensive industries; data envelopment analysis; Egypt

\section{Introduction}

Sustainable development has become one of the main concerns in many developing countries, and is integrated in Egypt's 2030 vision. The vision aims for a "new Egypt that will possess a competitive, balanced and diversified economy, dependent on innovation and knowledge, based on justice, social integrity and participation, characterized by a balanced and diversified ecological collaboration system, investing the ingenuity of place and humans to achieve sustainable development and to improve Egyptians' life quality," (Sustainable Development Strategy: Egypt Vision 2030). Towards the achievement of sustainable development, Egypt needs to address its energy issues in view of being amongst the highest energy intensive economies in the MENA region and worldwide (CAPMAS, 2018). Of special relevance to this is the present structure of Egypt's industry (especially manufacturing) which leans heavily towards energy and capital intensive activities. Nurtured by historical energy subsidies, and concessionary lending policies, energy-intensive industries have come to constitute 72 percent of Egypt's manufacturing output, on average for the period 2002-2014 covered by the present study (Source: Authors' calculations from "Annual Industrial Statistics" issued by the Central Agency for Public Mobilization and Statistics).

With a sizeable share of manufacturing output generated by energy intensive industries,

\footnotetext{
|'Assistant Professor of Economics, Faculty of Business and International Trade, Misr International University, Cairo, Egypt

${ }^{2}$ Associate Professor of Economics, Faculty of Business Administration, Economics and Political Science, The British University in Egypt, Cairo, Egypt
} 
Egypt's environmental bill is as sizeable. This has triggered interest in estimating environmental total factor productivity (henceforth ETFP) for Egypt's energy intensive industries over the period of study. Moreover, empirical literature points to an overestimated total factor productivity (henceforth TFP) when the environmental component is omitted (Rusiawan et al. 2015). Hence, incorporating the environmental dimension should provide for a realistic measure of total factor productivity. This will, in turn, have implications for choosing the appropriate source of energy in production, and the shift towards the use of renewable energy sources and reduced reliance on fossil fuels, all in the direction of achieving goals 7, 9, and 12 of the sustainable development goals (affordable and clean energy; industry innovation and infrastructure; responsible consumption and production).

ETFP is estimated through the use of the Malmquist index and data envelopment analysis (henceforth DEA). To the best of the authors' knowledge, no such estimation has been previously attempted, and the present study thereby aims to fill a gap in literature relevant to Egypt. This could also be of significance to countries with similarities in industrial structure and that are, perhaps, at similar stages of development. The rest of the paper is organized as follows: section 2 gives a profile of energy intensive industries in Egypt, section 3 reviews the literature theoretically and empirically; section 4 discusses the methodology used; section 5 gives the estimation results, and finally conclusion and policy implications are given in section 6 .

\section{Profile of Energy Intensive Industries in Egypt}

In general, the industrial sector in Egypt is characterised by small sized industries. But together with large scale industries, these are the major employers of workers (UNIDO, 2015). Food, metal products, textiles, furniture and electric devices are responsible for more than $72 \%$ of industrial employment (CAPMAS, 2014).

Energy intensive industries constitute 72 percent of Egypt's manufacturing output, on average for the period 2002-2014 (Source: calculated from CAPMAS Annual Industrial Statistics, various issues). Among these industries, refined petroleum products industry is the major contributor to industrial output in 2014, followed by basic metals (ferrous and non-ferrous) and non-metallic mineral products. Non-electrical machinery and fabricated metal products except machinery were the least contributors to industrial output in the same year (CAPMAS, 2014). With regard to employment, the textile industry was the largest employer of workers among energy intensive industries, followed by non-metallic mineral products and electrical machinery and equipment, while nonelectrical machinery, paper and pulp, and rubber products were least contributors (CAPMAS, 2014).

Regarding capital intensity of energy intensive industries in 2014, non- metallic mineral products had highest capital intensity, followed by basic metals (ferrous and non-ferrous) and textiles industries. The lowest energy intensive industry in capital usage is nonelectrical machinery, followed by fabricated metal products except machinery and rubber (CAPMAS, 2014).

Of special interest to the present paper is the energy use in energy intensive industries. Non-metallic mineral products rank highest in energy use, followed by basic metals 
(ferrous and non-ferrous) and industrial chemicals. However, it is important to highlight that there is a huge gap between these three industries and the remaining energy intensive industries with respect to energy use. Among the energy intensive industries, the lowest in energy use is non- electrical machinery, followed by fabricated metal products except machinery and electrical machinery and equipment (CAPMAS, 2014).

With reference to the level of $\mathrm{CO}_{2}$ emissions by energy intensive industries, we note that energy intensive industries have been always accused of releasing the highest levels of pollution emissions, and thereby reducing environmental quality and exacerbating environmental damage (Hassaballa, 2014). Among energy intensive industries in Egypt, basic metals (ferrous and non-ferrous) was the largest emitter of $\mathrm{CO}_{2}$ in the year 2014 . With a huge gap, it is followed by refined petroleum products industry and then by industrial chemicals and non-metallic mineral products (Source: World Bank "World Development Indicators" at http://datatopics.worldbank.org/world-developmentindicators $/$. The lowest emitter of $\mathrm{CO}_{2}$ is non-electrical machinery, followed by fabricated metal products except machinery and paper and pulp.

The profile of Egypt's energy intensive industries establishes two key facts. First, industries that produce relatively low levels of output are associated with the use of low levels of inputs, as well as the release of low levels of pollution emissions. Hence, the size of production is correlated with the amount of inputs used and with the pollution emissions level. This is in keeping with the scale effect, as identified in the literature. For instance, non-electrical machinery and fabricated metals except machinery industries are the least in terms of contribution to output, capital usage, energy use and $\mathrm{CO}_{2}$ emissions. Their low levels of output thus entail the use of low levels of inputs as well as the release of low levels of pollution emissions. In contrast, basic metals (ferrous and non-ferrous) being the second in terms of highest contribution to output, use of capital, and energy use, come first among energy intensive industries in releasing high levels of pollution emissions.

Second, there is a high degree of association between energy use and pollution emissions levels. Highest industries in terms of energy use are also the highest terms of releasing pollution emissions levels. This moves in line with the literature (for instance, Hassaballa (2014), Mani and Wheeler (1998)). For example, basic metals and industrial chemicals are among the highest industries with respect to energy use, and are at the same time among the highest industries in releasing pollution emissions level. In contrast, non-electrical machinery and fabricated metals except machinery are among lowest industries with respect to energy use, and are, at the same time, among the least in releasing pollution emissions levels.

These facts point to the importance of studying energy intensive industries in Egypt in depth so as to test for their effects on environmental quality, and thereby on achieving sustainable development goals. Estimating the environmental total factor productivity is of high relevance in this regard.

\section{Literature Review}

\subsection{Theoretical developments}

Traditional productivity analysis used to measure TFP ignores the environmental by-products of production (negative spill-overs). As such, this analysis 
assumes these by-products to be freely disposable. Furthermore, even if the traditional approach measures TFP with an environmental factor, it would require the inclusion of pollution valued at some market price. Such prices are not only difficult to measure, but also not easy to obtain. The development of the directional distance function (henceforth DDF) methodology, under the data envelopment non-parametric frontier analysis, has allowed for the incorporation of the negative by-products in productivity measurements, without the need for prices.

Initially, Caves et al. (1982) developed the popular input- and output-oriented Malmquist productivity index as the ratio of two input, and two output, distance functions, respectively, but assuming no technical inefficiency. Färe et al. (1994) dropped the assumption of no technical inefficiency, and extended the work of Caves et al. (1982) to develop a Malmquist index that could be decomposed into indices describing technical change and efficiency change. Furthermore, while Shephard's work which focused on conventional input- and output-oriented distance functions had showed the cost function to be the dual of the input distance function, and the revenue function to be the dual of the output distance function, Färe et. al (1994) showed how this provided the basis for decomposing revenue inefficiency into technical and allocative components (Färe, Grosskopf and Lovell 1994). The work of Färe and Grosskopf (1997) identified the DDF as the generalization of Shepard's distance functions, and extended further to show that the DDF is the dual of the profit function. The duality between the distance function and the profit function was later exploited by Färe, Grosskopf and Weber (1999) in a theoretical development and empirical application that decomposed profit efficiency into allocative efficiency and technical efficiency (Cooper and Lovell, 2000:1). Furthermore, DDFs could allow for output to be expanded while simultaneously contracting inputs. This was used further by Chung, Färe and Grosskopf (1997), and Ball et al. (2001) to model the joint production of 'desirable' and 'undesirable' outputs (negative by-products) using the Malmquist-Luenberger index to measure TFP. As such, the production of 'desirable' and 'undesirable' (bad) outputs is modelled while calculating the productivity of the decision making units (meanwhile allowing for the increase in desirable output and the decrease in the undesirable output). Moreover, DDFs avoided the problem of obtaining overestimated and misleading TFP estimates since environmental factors (i.e., the pollution emissions released with output produced) are accounted for.

\subsection{Empirical literature}

Much empirical literature has focused on China due to its heavy energy consumption. Literature has also further shown that China's growth depended heavily on investment in resources instead of improvements in TFP. The excessive use of energy, and the heavy investment in resources had environmental impacts which could not be ignored in productivity analyses (Fare, Grosskopf and Pasurka (2001)). This has motivated much applied research on China's growth-environment relation. Under this research falls work of Keting and Jianjian (2012), and Yang and Yang (2016), which used DDFs to illustrate the situation in which desirable and undesirable (bad) outputs are jointly produced.

Keting and Jianjian (2012) used the Malmquist-Luenberger index to measure 
environmental total factor productivity (henceforth ETFP). The index is the product of 'production efficiency' change $(\mathrm{MEFCH})$ and the 'technical progress' change (MTECH): $\mathrm{MI}_{t}^{t+1}=\mathrm{MEFCH}_{t}^{t+1} \times \mathrm{MTECH}_{t}^{t+1}$

MEFCH denotes change in efficiency that moves the decision-making unit (DMU) towards (or away from) the production frontier. The movement towards the frontier (also known as the 'catching up' effect) may come about through 'learning by doing', 'management efficiency', as well as the capacity to grasp existing technologies. MTECH denotes the technical progress which accounts for the DMU's technical innovation which may bring about a shift in the frontier itself. It is worth mentioning that the benchmark value for the MI, MEFCH and MTECH is 1. A value exceeding 1 denotes that the DMU experiences productivity improvement, improved efficiency and has made technical progress, respectively. A value less than one denotes a decline in any of the three (Keting and Jianjian, 2012:40).

Keting and Jianjian (2012) used as inputs to production 'capital', 'labour' and 'energy', with the desirable output measured as value added per (energy intensive) industry, and the undesirable output as sulphur dioxide $\left(\mathrm{SO}_{2}\right)$ emissions. The authors evaluated the growth in environmental total factor productivity of 38 industries in China during the period 1996-2009, and concluded that ETFP in China's energy intensive industries to be driven by technological progress, more than it is driven by efficiency change. This, in turn, implies much room for the industrial sector in China to grow its production efficiency.

In a further step, the authors also empirically tested the factors affecting growth in ETFP in China's energy intensive industries. They concluded that foreign direct investment (henceforth FDI) has a positive effect on ETFP growth a result of probable benefits brought about by the advanced technology used in foreign investments, the bulk of which went to China's chemical industries during the period of study. Meanwhile research and development (henceforth $R \& D$ ) had a negative effect on ETFP indicating problems in the institutional factors related to $\mathrm{R} \& \mathrm{D}$ activity in energy intensive industries. Moreover, R\&D investments largely came from state owned enterprises (henceforth SOEs) which dominated energy-intensive activity. Such SOEs were subject to soft budget constraints, and were more oriented towards bringing about short term political gains than long term gains that $\mathrm{R} \& \mathrm{D}$ types of investment bring about. As such, the expected long-term effects of R\&D are not realized. Another factor tested by the authors was the corporate environmental management capacity. This was defined as removal rate of industrial $\mathrm{SO}_{2}$ and was found to be positively correlated to ETFP indicating the environmental management played a key role in ETFP.

The distance function approach has been used to serve other empirical purposes. Yang and Yang (2016) compared the effects of China's energy saving and emissions reduction policies within its $11^{\text {th }} 5$-yr plan on the ETFP of 15 energy intensive industries. They found significant productivity increases in the smelting and pressing of ferrous metals and the manufacture of transport equipment, but decreased in the manufacture of nonmetallic mineral products, communications equipment and others, smelting and pressing of nonferrous metals, processing of petroleum. Other industries such as textile, and paper products experienced no substantial ETFP changes. 
The present study on Egypt's energy intensive industries has capitalized on works of Kutscher (1979), Mani and Wheeler (1998), and Yang and Yang (2016) to select the energy intensive industries for study. Despite the wide time span between the first two studies and the third, all three studies identify the same industries are being the energy intensive ones. Kutcher (1979) based the identification of energy intensive industries on their respective usage of oil, coal, electricity and gas based in input-output transactions tables, with further detailed use of labour and capital intensity data by industry from the U.S. Bureau of Labour Statistics. The author further categorized industries by most- and least-energy-intensive industries. Mani and Wheeler (1998) identified pollution-intensive industries based on actual emissions intensity (defined as emissions per unit of output). They also ranked those industries found which were identified as being highly airpolluting, highly water-polluting, and of high overall-pollution. Worthy of note is the very high association between energy- and pollution-intensity. Those industries identified by Kutscher (1979) as energy-intensive are themselves identified by Mani and Wheeler (1998) as pollution-intensive with almost the same descending rank of energy and pollution intensive industries, respectively. One exception is that Mani and Wheeler (1998) list of top ten pollution-intensive industries does not include electrical machinery and equipment, and non-electrical machinery, though these two industries have been identified by Kutscher (1979), and also by Yang and Yang (2016) as energy intensive.

Hence, the ten energy intensive industries studied in this paper are: basic metals (ferrous and non-ferrous); industrial chemicals; refined petroleum products; non-metallic mineral products; fabricated metal products except machinery; textiles; paper and pulp; rubber products; electrical machinery and equipment; and non-electrical machinery.

\section{Methodology}

Following mainstream literature and applied research, a DDF is used to model the production of desirable and undesirable outputs ${ }^{1}$, estimating ETFP using the Malmquist productivity index (defined as the ratio of two distance functions of time period $\mathrm{t}$ and $\mathrm{t}+1$ ) on a panel ten energy intensive industries in Egypt from 2002-2014.

$$
M_{t}^{t+1}=M E F C H_{t}^{t+1} \times M T E C H_{t}^{t+1}
$$

Where,

$$
\begin{aligned}
& M^{t}=\frac{D^{t}\left(x^{t+1}, y^{t+1}\right)}{D^{t}\left(x^{t}, y^{t}\right)} \\
& M^{t+1}=\frac{D^{t+1}\left(x^{t+1}, y^{t+1}\right)}{D^{t+1}\left(x^{t}, y^{t}\right)}
\end{aligned}
$$

Since the choice of times t or $\mathrm{t}+1$ is arbitrary, a solution is to take the geometric mean, rendering the $\mathrm{M}$ index as:

$$
M_{t}^{t+1}=\left(\frac{D^{t}\left(x^{t+1}, y^{t+1}\right)}{D^{t}\left(x^{t}, y^{t}\right)} / \frac{D^{t+1}\left(x^{t+1}, y^{t+1}\right)}{D^{t+1}\left(x^{t}, y^{t}\right)}\right)^{1 / 2}
$$

${ }^{1}$ It is noteworthy that the desirable and undesirable outputs are assumed to be jointly weakly disposable, whereby the firms experience a cost due to their disposal of pollutions. Such a cost diverts available resources away from producing the maximum level of good output attainable with the given resources. The desirable and undesirable outputs are also assumed to be null-joint which means that the production of the good output is always associated with the production of a certain quantity of bad output. 
As inputs and outputs ( $\mathrm{x}, \mathrm{y})$ in any DEA model are assumed to be positive, and since the Data Envelopment Analysis Programme (DEAP) used in the computation does not recognize negative numbers, the direct approach for incorporating undesirable outputs (accounted for in negative values under the Malmquist-Luenberger index) of Chung, Färe and Grosskopf (1997) could not be used. Two transformations were thus made to account for the undesirable output: the additive and reciprocal transformations. According to Scheel (2001), the additive approach was introduced by Koopmans (1951) and used by many researchers such as Berg et al. (1992). It allows for adding a constant to the undesirable output such that its sum when added to the lowest negative value in the data series is equal to 0.001 or 1 . A stricter method is to use the reciprocal (or the multiplicative inverse) as suggested by Golany and Roll (1989). This method was used by many researchers such as Athanassopoulos and Thanassoulis (1995). Hence, the Malmquist index after transformations is used in this study instead of the MalmquistLuenberger index to measure ETFP. This is conducted in constant returns to scale $(\mathrm{CRS})^{2}$ and as an output-orientated distance function.

Therefore, a total of three MI computations where conducted to measure ETFP for energy intensive industries in Egypt: the first and second entailed computing MI after applying the additive and reciprocal transformations approach to account for the undesirable output, respectively; the third entailed computing MI without considering the undesirable output in order to determine whether the estimated TFP is indeed overestimated if the undesirable output is omitted, as suggested in the literature.

It is important to highlight that some traditional techniques used to measure productivity include the Törnqvist and Fisher index. However, this requires the use of market prices of both inputs and outputs when incorporating an undesirable output for which there is no market valuation in reality. Accordingly, this further nominated the use of the Malmquist index.

\subsection{Variable description}

-Desirable output is measured as the value of output in market prices.

-Undesirable output is often measured as the industrial sector's $\mathrm{SO}_{2}$ emissions (Keting and Jianjian (2012) and other studies). However, for absence of $\mathrm{SO}_{2}$ emissions data for Egypt, $\mathrm{CO}_{2}$ emissions from combustion of fuels in industry (manufacturing industries and construction) in millions of metric tons were used instead. Our analysis would have been hindered by the absence of industry-specific $\mathrm{CO}_{2}$ emissions for Egypt. We

2 Note that O'Donnell (2012) argues that CRS is generally an assumption that is necessary but not sufficient for a Malmquist TFP index to be interpreted as a measure of output growth divided by a measure of input growth, which is how many economists define productivity change (O'Donnell 2012:258). However, this has not been the direction of much mainstream literature on this issue (see for example, Jeon and Sickles (2004)). Further testing for whether technology exhibits CRS or otherwise, the production function was estimated, and the statistically significant coefficients on labour, capital and energy verified that technology exhibits variable returns to scale. However, as per Banker, Charnes and Cooper (1984), the conclusive test is to use compare the CRS and VRS specifications. If the technical efficiency change scores for the DMUs obtained from the CRS DEA are not different from the VRS DEA, then there are no scale inefficiencies (under the technical efficiency change score) and thus CRS do exist for the DMU. Comparison proved the TE change scores to be identical for all DMUs under CRS and VRS, and thus CRS is concluded to be the correct specification. 
therefore calculated the share of the each industry's output in total manufacturing output multiplied by total manufacturing and construction $\mathrm{CO}_{2}$ emissions as a proxy for industry-specific $\mathrm{CO}_{2}$ emissions.

-Inputs are labour, capital and energy. Labour is measured as the total number of employees in the industry by year. Capital is measured as the value of end of year stock of fixed assets. Energy is measured as expenditure on energy and electricity by the industry by year.

Desirable output, capital and energy expenditure values by industry were all deflated using the producer price index of the respective industry by year.

\subsection{Data}

Data for the desirable output and for all inputs were drawn from the "Annual Industrial Statistics" issued by Egypt's Central Agency for Public Mobilization and Statistics (CAPMAS). Data for the producer price index by industry from CAPMAS. Data for the undesirable output were obtained from the World Bank "World Development Indicators".

\section{Estimation Results}

Table 1 below shows the results of ETFP (measured by the MI), efficiency change and technical progress in Egypt's ten energy intensive manufacturing industries from 2002-2014. The industries are shown in the table in their order of decreasing energy intensity (based on their energy/output ratio calculated from the data). MI is computed after applying the reciprocal transformations of the undesirable output ${ }^{3}$. The geometric mean of ETFP for the ten industries of study is also given 'with' and 'without' incorporating the pollution emissions released.

Table 1: Malmquist index for energy intensive industries and their geometric mean in Egypt (using the reciprocal transformation of undesirable output), 2002-2014

\begin{tabular}{|l|c|c|c|}
\hline Industry & MI (=ETFP) & MEFCH & MTECH \\
\hline 1- Non-metallic mineral products & 1.003 & 0.939 & 1.068 \\
\hline 2- Basic Metals (ferrous and non- ferrous) & 1.123 & 0.982 & 1.143 \\
\hline 3- Textiles & 0.986 & 0.910 & 1.084 \\
\hline 4- Paper and Pulp & 0.974 & 1.007 & 0.967 \\
\hline 5- Industrial chemicals & 1.050 & 0.953 & 1.102 \\
\hline 6- Rubber products & 0.993 & 0.998 & 0.995 \\
\hline 7- Fabricated metal products except machinery & 1.060 & 1.025 & 1.034 \\
\hline 8- Refined petroleum products & 1.089 & 1.000 & 1.089 \\
\hline 9- Non-electrical machinery & 1.052 & 1.000 & 1.052 \\
\hline 10- Electrical machinery and equipment & 0.724 & 1.000 & 0.724 \\
\hline MEAN all industries & $\mathbf{0 . 9 9 9}$ & $\mathbf{0 . 9 8 1}$ & $\mathbf{1 . 0 1 9}$ \\
\hline MEAN all industries (excluding undesirable output) & 1.056 & 0.965 & 1.094 \\
\hline
\end{tabular}

Source: estimation results

${ }^{3}$ For results of ETFP using the additive transformation of undesirable output see the Appendix. 
On average, ETFP for the ten energy intensive industries has remained almost unchanged, with 'technical progress' contributing 1.9 improvement, almost fully outweighed by an equal efficiency deterioration. Effectively, the ten industries have not exhibited an efficiency enhancement that would move them anywhere close to the frontier, nor a technical innovation that would have brought about a frontier shift. This is different from the results obtained by Keting and Jianjian (2012) on Chinese industries in which there was an improvement in ETFP mainly driven by technical progress.

Our results further indicate that when the undesirable output is excluded, TFP is indeed overestimated. It was reflecting an unrealistic 5.6 percent betterment (which may have been brought about by a 9.4 percent technical progress partly eaten away by 3.5 percent deterioration in efficiency). Such an overestimate of TFP was bound to result from the neglect of negative externalities and from overlooking environmental regulations. Moreover, it further points to the possibility that firms might have been able to produce more with the given resources as they were not required to divert resources away from production towards the reduction of pollutants (Nanere et al., 2007). These results are also similar to the findings of Keting and Jianjian (2012).

At the industry level, six industries showed an improved ETFP: basic metals; refined petroleum products; fabricated metal products except machinery; non-electrical machinery; industrial chemicals; non-metallic mineral products. Basic metals appears to have experienced technical progress, and efficiency decline. Refined petroleum showed ETFP improvement primarily driven by technical progress. Non-metallic mineral products' ETFP improvement was primarily technical-progress-driven with an efficiency decline. Fabricated metal products except machinery showed ETFP improvement to be driven by improved efficiency and technical progress. Lastly, industrial chemicals showed technical progress and an efficiency decline, while non-electrical machinery had only technical progress with no efficiency change.

Lastly, Figure 1 below summarizes the above results:

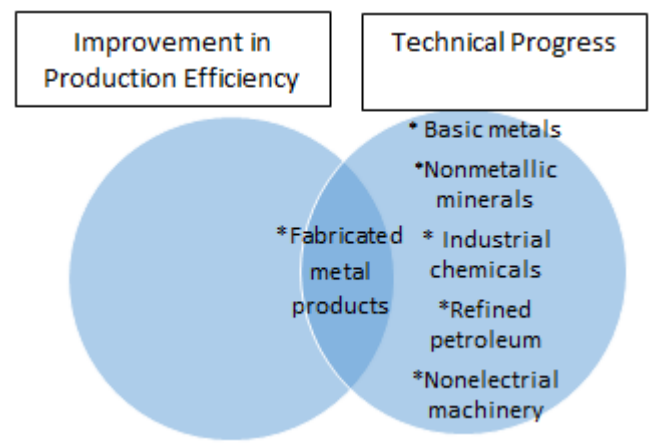

Figure 1:Energy intensive industries with improved ETFP

Source: authors' results

The remaining four industries have exhibited ETFP deterioration. In particular, electrical machinery has shown the greatest deterioration which has resulted from a technical regress. Rubber has shown ETFP deterioration owing to both efficiency decline and 
technical regress. Textiles have shown ETFP deterioration owing to efficiency deterioration eating away technical progress. Meanwhile, paper and pulp's ETFP has also deteriorated, primarily owes to technical regress (largely eating away any efficiency improvement). Figure 2 below summarizes the above results.

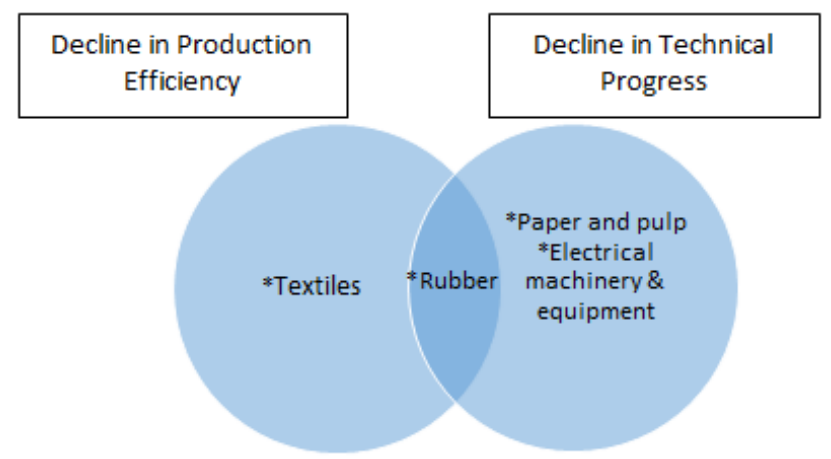

Figure 2: Energy intensive industries with deteriorated

Source: authors' results

\section{Conclusion and Policy Implications}

This research paper estimated the ETFP for Egypt's energy intensive industries over the period 2002-2014. A DDF approach was used to model the production of desirable and undesirable outputs in which the ETFP was estimated using the Malmquist Index on a panel data set of ten energy intensive industries. This was done after applying both reciprocal and additive transformations. The results showed that, on average, ETFP for the ten energy intensive industries has remained almost unchanged, with 'technical progress' contributing 1.9 improvement, almost fully outweighed by an equal efficiency deterioration. In addition, the results varied across industries. For instance, fabricated metal products except machinery industry has both efficiency and technical progress change, in contrast to rubber in which there are both a decline in production efficiency and in technical progress. All other industries lie in between these two ends. Another important finding is that when the undesirable output is excluded, TFP is indeed overestimated. This highlights the importance of incorporating environmental effects to ensure obtaining more realistic TFP estimation.

After displaying these results, some policy implications on the general and specific levels are given below. Keting and Jianjian (2012) identified general policy implications as: the enhancement of technological innovation; upgrading energy intensive industries; promoting energy saving investment; relying more on renewables and energy conservation; encouraging green growth and giving incentives to firms to abide by green growth objectives. We have found the above policy implications to be of equal relevance to Egypt. We have further identified how these policy implications may be aligned with the achievement of one or more of the following SDG goals: 7 (affordable and clean energy); 9 (industry innovation and infrastructure); 12 (responsible consumption and production). 
Table 2: The alignment of general policy implications with SDG goals

\begin{tabular}{|l|c|c|c|}
\hline General policies & $\begin{array}{c}\text { Goal 7 } \\
\text { (affordable and } \\
\text { clean energy) }\end{array}$ & $\begin{array}{c}\text { Goal 9 (industry } \\
\text { innovation and } \\
\text { infrastructure) }\end{array}$ & $\begin{array}{c}\text { Goal 12 (responsible } \\
\text { consumption and } \\
\text { production) }\end{array}$ \\
\hline $\begin{array}{l}\text { Enhancement of technological } \\
\text { innovation }\end{array}$ & $\checkmark$ & $\checkmark$ & \\
\hline $\begin{array}{l}\text { Upgrading energy intensive } \\
\text { industries }\end{array}$ & $\checkmark$ & $\checkmark$ & \\
\hline $\begin{array}{l}\text { Promoting energy saving } \\
\text { investment }\end{array}$ & $\checkmark$ & & \\
\hline $\begin{array}{l}\text { Relying more on renewables } \\
\text { and energy conservation }\end{array}$ & & $\checkmark$ & $\checkmark$ \\
\hline $\begin{array}{l}\text { Encouraging green growth and } \\
\text { giving incentives to firms to } \\
\text { abide green growth objectives. }\end{array}$ & & & \\
\hline
\end{tabular}

Source: compiled by the Authors

Enhancing technological innovation can be achieved through applying more R\&D and encouraging large corporations to give grants to students/workers to study abroad for greater knowledge exchange. Upgrading energy intensive industries may come about through the adoption of up-to-date energy saving techniques of production to help conserve energy. Energy conservation can also be realized through greater use of renewables (solar energy in specific) together with the application of environmental management systems. Upgrading these industries may be further achieved through giving incentives, tax breaks, and financial assistance to encourage energy saving investments. With reference to green growth, Egypt remains in need of an integrated framework to support the greening of industries, with commitments to ensuring strict inspection, proper evaluation, governance and a fair system of rewards and penalties. Within that framework, the environmental performance of firms must be closely monitored, with a system of rewards/penalties in place.

Furthermore, specific policy implications deduced from the results obtained for Egypt would be:

1) Three of the industries especially merit greater focus and further study: basic metals, fabricated metal products except machinery and rubber. It is highly important to study and analyse the reasons behind the success of basic metals and fabricated metal products except machinery in their improved technical progress. This may yield key lessons for other industries. Similarly, the rubber industry should be carefully studied to identify and alter the possible conditions behind the decline in both production efficiency and in technical progress.

2) Apply more R\&D in electrical machinery and equipment, and paper and pulp industries to enhance innovation and creativity as a way to achieve technical progress. This enhancement can be achieved through university-business collaboration in R\&D with relevance to the industry, as well as the exchange of R\&D personnel between different 
sectors (private/public or local/ international) for greater exchange of knowledge.

3) Efficiently utilize resources and management at the firm level to achieve efficiency improvements in refined petroleum, non-electrical machinery industries. This is because the results highlighted that there was no efficiency change within these two industries. This effort should be multiplied even further in the cases of textiles which showed an efficiency decline. Efficiency improvements can be achieved through both operational and organizational developments. These can be realized through the efficient use of resources with minimal waste, eradication of redundant processes, the provision of supporting organizational activities (such as finance functions) in a manner harmonious with production, possible incentives to workers, as well as linking wages to productivity. At the management level, well-defined goals and appropriate planning, with a degree of flexibility in the face of constraints are also required.

4) Ensure that the environmental dimension be incorporated in the analysis of total factor productivity for all industries to have realistic estimates, not to mention energyand pollution-intensive ones. This is deduced from the result of overestimation of TFP when the environmental dimension was excluded or not accounted for.

It is thus evident from research findings that the economy and the environment are still insufficiently linked, which is not in harmony with Egypt's aims for sustainable development as demonstrated in its 2030 vision. Not only so, but it is also important to highlight that the present research faced two key data limitations. The first was the absence of $\mathrm{SO}_{2}$ emissions data for Egypt. The second was the absence of industryspecific $\mathrm{CO}_{2}$ data. As such, the researchers have resorted to a proxy measure of $\mathrm{CO}_{2}$ by industry relying on sectoral contribution to output to calculate industry share in total $\mathrm{CO}_{2}$ emissions. Data availability is a hindrance to environmental studies which are of rising academic and applied importance.

There is much room for future research especially with reference to the geographical importance of the environmental impacts of the energy intensive industries studied in this paper. Such research would entail a zoom on the geographic regions in which these industries are located/concentrated. This would further our understanding of whether there are differences in ETFP by region, and whether these differences are stemming from a higher/lower concentration of energy intensive industries. This is expected to be of primary relevance to Egypt as it draws (or redraws) its industrial map particularly in view of a pressing need to attract foreign direct investment. Moreover, further research can also replicate this analysis for energy intensive industries in other developing countries, with potential for a deeper understanding of where and how they differ, and what institutional factors may explain their similarities or differences.

\section{References}

Annual Industrial Statistics (2002-2014). Issued by Egypt's Central Agency for Public Mobilization and Statistics (CAPMAS).

Athanassopoulos, A.D., Thanassoulis, E. (1995) Separating market efficiency from profitability and its implications for planning. Journal of Operational Research Society 46:20-34.

Ball, V.E., Färe, R., S. Grosskopf, R., Nehring (2001) Productivity of the US agricultural sector: the case of undesirable outputs. In Hulten, C.R., Dean, E.R., Harper, M.J. (Eds). New Developments in Productivity Analysis, The University of Chicago Press, U.S.A. 
Banker, R.D., A. Charnes and W.W. Cooper (1984). "Some Models for Estimating Technical and Scale Inefficiencies in Data Envelopment Analysis." Management Science 30(9): 1078-1092, in Coelli, T. J. (1996). A guide to DEAP version 2.1: A data envelopment analysis (computer) program. Centre for Efficiency and Productivity Analysis Working Papers, University of New England, Australia, 8/96.

Berg, S.A., Forsund, F.R., Jansen, E.S. (1992) Malmquist indexes of productivity growth during the deregulation of Norwegian banking. Scandinavian Journal of Economics 9:89.

Caves, D.W., L.R. Christensen and W.E. Diewert (1982). "The Economic Theory of Index Numbers and the Measuremnt of Input, Output, and Productivity." Econometrica 50: 1393-1414.

Central Agency for Public Mobilization and Statistics (CAPMAS) (2018) https://www.capmas.gov.eg/ - (2014) https://www.capmas.gov.eg/

Chung, Y.H., Färe, R.,Grosskopf, S. (1997) Productivity and undesirable outputs: a directional distance function approach. Journal of Environmental Management 51:229-240.

Cooper, W., Lovell, C. (2000) New approaches to measures of efficiency in DEA: an introduction. Journal of Productivity Analysis 13:91-92.

Egypt's 2030 Vision. at http://sdsegypt2030.com/?lang=en

Färe, R., Grosskopf, S. (1997) Intertemporal Production Frontiers: With Dynamic DEA, 1st edn. Kluwer Academic Publishers, Massachusetts.

Färe, R., Grosskopf, S. (2000) Theory and application of directional distance functions. Journal of Productivity Analysis 13:93-103.

Färe, R., Grosskopf, S., Lovell, C.A.K., 1994. Production Frontiers, $1^{\text {st }}$ edn. Cambridge University Press, Cambridge.

Färe, R., Grosskopf, S., Pasurka Jr., C.A. (2007) Pollution abatement activities and traditional productivity. Ecological Economics 62:673-682.

Färe, R., Grosskopf, S., Weber, W. (1999) The effect of risk based capital requirements on profit efficiency in banking. Oregon State University working paper.

Golany, B., Roll, Y (1989) An application procedure for DEA. Omega 1:237-250.

Hassaballa, H. (2014) Testing for Granger causality between energy use and foreign direct investment Inflows in developing countries. Renewable and Sustainable Energy Reviews 31: 417-426.

Jeon, Byung M., and Robin C. Sickles (2004) The Role of Environmental Factors in Growth Accounting. Journal of Applied Econometrics 19:567-591.

Keting, S., Jianjian, G. (2012) An empirical study of China's energy- intensive industries' growth based on environmental total factor productivity. China Economist 7:3749.

Koopmans, T. C. (1951) An analysis of production as an efficient combination of activities. In Koopmans, T. C. (Ed.): Activity Analysis of Production and Allocation, Proceeding of a Conference, pp.33-97, John Wiley and Sons Inc., London.

Kutscher, R.E. (1979) The influence of energy on industry output and employment. Monthly Labour Review 102:3-10.

Mani, M., Wheeler, D.(1998). In search of pollution havens? Dirty industry in the world economy, 19601995. Journal of Environment and Development 7(3):215-247.

Nanere, M., Fraser, I., Quazi, A., D’Souza, C. (2007) Environmentally adjusted productivity measurement: An Australian case study. Journal of Environmental Management 85:350-362.

O'Donnell, C.J. (2012) An aggregate quantity framework for measuring and decomposing productivity change. Journal of Productivity Analysis 38:255-272.

Rusiawan, W., Tjiptoherijanto, P., Suganda, E., Darmajanti, L. (2015) Assessment of Green Total Factor Productivity Impact on Sustainable Indonesia Productivity Growth. Procedia Environmental Sciences 28: $493-501$.

Scheel, H. 2001. Undesirable Outputs in Efficiency Valuations. European Journal of Operational Reseach 132, 400-410.

Sustainable Development Strategy: Egypt Vision 2030, http://sdsegypt2030.com/?lang=en

The Sustainable Development Goals, https://www.un.org/sustainabledevelopment/energy/

World Bank "World Development Indicators", https://data.worldbank.org/data-catalog/worlddevelopment-indicators

Yang, M., Yang, F. (2016) Energy efficiency policies and energy productivity improvements: Evidence from China's manufacturing industries. Emerging Markets Finance and Trade 52: 1395-1404. 
United Nations Industrial Development Organisation (UNIDO) (2015) Industrial Energy Efficiency in Egypt.

\section{Appendix}

Malmquist index for energy intensive industries arranged in order of decreasing energy intensity and their geometric mean in Egypt (using the additive transformation of undesirable output), 2002-2014

\begin{tabular}{|l|c|c|c|}
\hline Industry & MI (=ETFP) & MEFCH & MTECH \\
\hline 1- Non-metallic mineral products & 1.020 & 0.982 & 1.038 \\
\hline 2- Basic Metals (ferrous and non-ferrous) & 1.087 & 0.982 & 1.107 \\
\hline 3- Textiles & 0.993 & 0.919 & 1.081 \\
\hline 4- Paper and Pulp & 0.963 & 1.037 & 0.929 \\
\hline 5- Industrial chemicals & 1.034 & 1.003 & 1.032 \\
\hline 6- Rubber products & 1.038 & 1.041 & 0.997 \\
\hline 7- Fabricated metal products except machinery & 1.047 & 1.031 & 1.016 \\
\hline 8- Refined petroleum products & 1.073 & 1.000 & 1.073 \\
\hline 9- Non-electrical machinery & 1.036 & 1.000 & 1.036 \\
\hline 10- Electrical machinery and equipment & 0.925 & 1.000 & 0.925 \\
\hline MEAN all industries & $\mathbf{1 . 0 2 1}$ & $\mathbf{0 . 9 9 9}$ & $\mathbf{1 . 0 2 2}$ \\
\hline MEAN all industries (excluding undesirable output) & 1.056 & 0.965 & 1.094 \\
\hline
\end{tabular}

Source: Authors' results 